\title{
O ACORDO ENTRE O SENSÍVEL E O INTELIGÍVEL
}

The agreement between the sensible and the intelligible

\section{Maria Fernanda Andrade Saiani Vegro'}

RESUMO Este artigo apresenta uma investigação sobre a metodologia de ensint proposta pelo professor dr. Sílvio Soares Macedo para a disciplina AUP 652, vinculada ao Departamento de Projeto e inserida na grade curricular do segundo semestre do curso de Arquitetura Urbanismo da Universidade de São Paulo, articulada com a fenomenologia da perçepção de Maurice Merleau-Ponty (1908/1961). A filosofia merleau-pontiana se caracteriza fundamentalmente, por estabelecer relações entre sujeito, natureza e objeto, marcadas por um pensamento engajado no mundo. Esse arco reflexivo desdobra-se a partir do exercício da invenção do projeto como um perpétuo "fazer-se" em camadas, no qual se distingue sua origem mais primária, da lembrança e do contato com corpo, até atingir uma ordenação lógica. O objetivo da disciplina AUP 652 é desenvolver nos estudantes a compreensão de escalas e capacidade de abstrair e representar o espaço, com ênfase no papel comunicacional do projeto que deflagra a constatação de um mundo único que se engrandece no estímulo da participação ativa entre professor e alunos.

PALAVRAS-CHAVE: Invenção, Projeto, Espaço, Corpo, Lógica.

ABSTRACT This article presents an investigation into the teaching methodology proposed by PhD professor Silvio Soares Macedo for the discipline AUP 652, linked to the Project Department, part of the curriculum of the second semester of Architecture and Urbanism at the University of São Paulo, articulated with the phenomenology of perception of Maurice Merleau-Ponty (1908-1961). Merleau-Ponty's philosophy is characterized primarily on establishing relationships among man, nature and object, marked by an engaged thought in the world. This reflexive arc is spread through the exercise of a project creation as a perpetual "doing" in layers, which distinguishes its most primary origin, memory and body contact, to achieve a logical order. The aim of the course AUP 652 is to develop in students an understanding of scales and the ability to abstract and represent the space, emphasizing the project's meaning that triggers the realization of a single world that is magnified in stimulating active participation between teacher and students.

KEYWORDS: Invention, Project, Space, Body, Logic.

\section{How to cite this article:}

VEGRO, M. F. A. S. O acordo entre o sensível e o inteligível.

Gestão e Tecnologia de Projetos, São Carlos, v. 11, n. 1, p. 71-82, jan./jun. 2016.

http://dx.doi.org/10.11606/gtp.v11i1.98672

Fonte de financiamento:

Coordenação de

Aperfeiçoamento de Pessoal

de Nivel Superior (Capes).

Conflito de interesse:

Declaram não haver.

Submetido em: 31 maio 2015

Aceito em: 28 out. 2015 


\section{INTRODUÇÃO}

Para a formação do futuro arquiteto, a questão do desenho nas disciplinas de Projeto - seja em escala micro do edifício, seja em escala macro para a cidade e paisagem - cumpre papel de destaque como ferramenta imprescindível de comunicação, presente na relação educador/educando, arquiteto/cliente, arquiteto/comunidade.

A ênfase na vida escolar do aluno restringe-se à prática da escrita de textos e posse de códigos matemáticos. Nas novas gerações, o desenho e a ação de projetar como expressão de ideias e conhecimento, ato criador, aponta para um deslocamento preocupante do suporte papel para a tela do computador. Tal procedimento prescinde da etapa da apropriação da percepção e sensibilidade visual que o desenho no suporte papel propicia, consequentemente, o estudante (por meio de comandos como o "zoom") perde a referência dimensional de seu projeto numa busca "veloz" por resultados imediatos à custa do mínimo esforço, quadro que elimina os diferentes processos inerentes ao projeto de arquitetura e urbanismo.

Outro problema relevante para as disciplinas que contam com o exercício do projeto é a questão do atendimento por parte dos professores às equipes de trabalho, como ocorre no caso da Faculdade de Arquitetura e Urbanismo da Universidade de São Paulo (FAU-USP), que conta com número muito grande de alunos.

As equipes de trabalho da disciplina AUP 6521 são estimuladas com novos desafios, na forma de exercícios preliminares, que servem de fundamento para o trabalho realizado em cada aula. A abordagem aos grupos de alunos, muitas vezes requisita um tempo de espera. No caso da disciplina AUP 6522 as equipes mantém-se sempre ocupadas no estúdio, desenvolvendo o exercício proposto pelos professores no início da aula.

Cada exercício desenvolvido pelas equipes representa uma parte de um todo que estabelece constante relação com os conhecimentos adquiridos no correr do curso até sua conclusão, na qual essas partes possuirão uma dinâmica própria, um entrelaçamento verificável nos resultados finais da disciplina.

Após o desenvolvimento dos exercícios no estúdio ocorre o retorno à sala de aula com uma discussão sobre os trabalhos realizados no decorrer da aula, com o intuito de proporcionar um momento de reflexão, aprofundamento e retificação do trabalho elaborado que delimita um campo aberto de ação por parte dos alunos. O projeto é sempre retomado, um movimento que estabelece novo movimento por parte das equipes e se constrói de forma estratificada, isto é, a cada novo desafio agregam-se novos pontos de vistas possíveis, desenvolve-se a visão crítica dos alunos. A transmissão do conteúdo da disciplina se constrói no tempo e no espaço, pois a cada novo exercício proposto verifica-se um saber acumulativo.

Para a compreensão inteligível da espacialidade, a metodologia do professor dr. Sílvio Soares Macedo propõe considerar o ato de projetar, ou seja, um meio de coexistência de diferentes aspectos que encontram sua legitimidade no corpo e na valorização da experiência do aluno. Desse modo, configura-se o projeto num universo amplo, constituído em camadas, que revela a pré-objetividade como condição de seu fundamento.

O objetivo da disciplina é desenvolver habilidades nos estudantes que confiram um domínio sobre o conceito de espaço e suas implicações em nível objetivo e subjetivo, como no caso o uso das escalas micro, média e macro, circulação, espaços públicos e privados, topografia, tipologias,

Em 2012, a autora participou da aula de Pedagogia Aplicada para Arquitetura e Urbanismo do programa de pós-graduação da Faculdade de Arquitetura e Urbanismo da Universidade de São Paulo (FAU-USP), na qual o professor Sílvio Soares Macedo descreveu sua experiência como docente no Departamento de Projeto da FAU-USP. A partir desse primeiro contato, a autora assistiu algumas de suas aulas na graduação e entrevistou alguns alunos. A fenomenologia de Merleau-Ponty foi o instrumental reflexivo utilizado em sua pesquisa de mestrado, chamou-lhe a atenção a imbricação dessa teoria com a metodologia utilizada para o ensino de projeto do professor Sílvio Soares Macedo.

A disciplina é realizada duas vezes por semana, tendo cada aula quatro horas de duração. 
gabarito, fundamentos teóricos da formação e transformação da paisagem para a representação de projetos de espaços livres.

\section{O CONCEITO DE “RAZÃO ALARGADA" PARA O ENSINO DO PROJETO}

Afilosofia eprincipalmenteaindagaçãofilosóficapodeseruminstrumento muito rico para a arquitetura. A interface dos elementos perceptivos que fundamentam o projeto arquitetônico com a fenomenologia de Maurice Merleau-Ponty irá fornecer aqui alguns pressupostos teóricos para a compreensão do movimento do exercício da invenção, pois em sua origem dirige-se ao ser e prescinde em sua atividade de qualquer atitude solipsista. Essa posição - denominada na filosofia de "solipsismo", do latim solusipsi (somente si mesmo) - confere consciência a um único ser. A existência de outros seres conscientes seria apenas uma ilusão. Para Merleau-Ponty, o solipsismo é insustentável, pois a percepção do outro funda a moralidade. "O reconhecimento, no próprio coração da experiência mais individual, de uma contradição fecunda que a submete ao olhar do outro - é o remédio para o ceticismo e o pessimismo" (MERLEAU-PONTY, 1990, p. 65). Tal quadro se justifica na necessidade emergente para a arquitetura de elaborar novas alternativas que coloquem o ser humano no centro de sua cena, incitem o debate, o pensamento complexo, a visão crítica, um pensamento que pensa a si mesmo a partir de uma "situação", uma práxis que abandona radicalmente a ilusão de uma objetividade "pura" ou uma subjetividade "pura" e constrói-se por um pensamento encarnado no mundo. Uma noção de experiência fecunda que torna o diálogo entre filosofia e arquitetura não uma explicação ou descrição, mas uma interrogação interminável.

Os objetos criados na cultura não se definem unicamente como físicos, mas possuem uma visibilidade sustentada por uma invisibilidade, uma latência, ou seja, trazem implicitamente em sua gênese a marca da ação humana que atravessa o tempo e inaugura o porvir. Para Merleau-Ponty, o corpo "situado" no mundo, sujeito da percepção, deforma o objeto numa série de perspectivas que não o esgotam. Filosofia "produtiva” cuja liberdade não é absoluta, mas configura-se numa determinada "situação" exige uma decisão que se "entranhe no porvir, que algo tenha sido feito por ela, que o instante seguinte se beneficie do precedente e sem ser necessitado, seja pelo menos solicitado por este" (MERLEAU-PONTY, 1999, p. 586).

$\mathrm{O}$ projeto em arquitetura e urbanismo, mediado pela linguagem do desenho, constitui um agente para o favorecimento da comunicação entre as diversas camadas sociais. "Entrar em si", "sair de si" rumo ao "outro", exercício de invenção, a ação do projeto aponta para a temporalidade sentida como tarefa intencionalmente estruturadora de fenômenos complexos. Origina-se da memória, percepção, do repertório adquirido de cada indivíduo na sociedade, em direção ao porvir. Tomado como uma "experiência radical", o projeto comporta uma dialética de abertura capaz de expressar autenticidade para a obra arquitetônica presente não no conforto, mas na tensão entre escolhas possíveis.

Para o arquiteto Vittório Gregotti (2010), os problemas postos pela arquitetura não devem preceder as soluções possíveis, isto é, observados passivamente e solucionados em seguida, mas, "o problema deve estar implicado [...] evoluir e resolver-se ao longo dos diversos níveis do processo" (p. 117). De acordo com esse ponto de vista, a experiência do "fazer" arquitetura é valorizada, as respostas para os seus problemas são reveladas no desdobramento dessa mesma ação e não se encontram numa consciência apartada do mundo.

Romper um "universal de sobrevoo" e inserir a presença de "outrem" com suas idiossincrasias numa região simbolicamente intersubjetiva, enquanto meio selvagem de coexistência, desde onde os objetos culturais assumem novas significações e imprimem dialeticamente o movimento da 
“alternância sujeito-objeto” é circunscrever a ação do projeto arquitetônico num circuito alargado, reflexivo e crítico ${ }^{3}$. Movimento de uma experiência que se revela ao fazer-se, imprevisível, aberta, democrática sempre retomada e questionada, inacabada, fecunda que não se estabelece na forma de enunciados, teses, conceitos fechados, ideias definitivas, mas como diz Merleau-Ponty, uma experiência geradora de matrizes de ideias que "dá o que pensar". Segundo o autor, "pensar não é possuir objetos de pensamento, é circunscrever através deles um domínio por pensar, que, portanto, ainda não pensamos” (MERLEAU-PONTY, 1985, p.176). Por meio da expressão, que ocupa destaque na filosofia de Merleau-Ponty, ocorre a valoração da experiência do sujeito como portal de acesso para o mundo cultural e histórico. Uma síntese temporal que inclui a criação como um processo de retomada na atualidade de obras póstumas, iluminadas em seus excessos ou lacunas que nesse mesmo ato desenha o porvir"

$\mathrm{O}$ recuo aos fundamentos pré-objetivos do projeto deve precisamente revelar a gênese do mundo objetivo, pois é o esquecimento dessa constituição que conduz ao prejuízo do mundo. Para Merleau-Ponty (1995), a ciência "é uma percepção que esquece suas origens e se crê acabada” (p. 69, 89). Em uma nota de sua obra Fenomenologia da percepção (1945) - que está longe de ser considerada puramente fenomenológica, mas que é a mais referenciada entre os arquitetos fenomenólogos ${ }^{5}$-, o autor denuncia: "ainda que tenham considerado uma obra de psicologia, ela é na realidade uma ontologia” (p. 230).

À luz dessa perspectiva, cabe destacar que a fenomenologia/ontologia de Merleau-Ponty situa-se na busca de uma relação entre a atitude natural e a atitude fenomenológica e não na exclusão de uma pela outra. Edmund Husserl (1859-1938), criador da fenomenologia, expõe sua doutrina da "dupla atitude" que opõe às "ciências dogmáticas" as "ciências filosóficas" e explica que as ciências que provêm da atitude dogmática se dirigem às coisas para explicitá-las, enquanto as ciências filosóficas não se dirigem ao mundo, mas, ao conhecimento. Para o autor, na "atitude natural" o interesse se dirige ao "ser objetivo", ao objeto "puro e simples", abrindo o acesso ao conhecimento objetivo. A "atitude fenomenológica" é considerada por Husserl como situada numa dimensão completamente nova, pois em regime de redução não são "às coisas" que ela se dirige, mas aos inúmeros modos de doação dos objetos "não investiga os objetos que o pesquisador de outras ciências investiga, mas o sistema completo dos atos de consciência possíveis, significações que justamente se relacionam a esses objetos” (Ibidem, p. 178). (HUSSERL apud MOURA, 2006, p.15). Para Husserl, então, "nunca haverá 'uma fenomenologia do ser'. [...] Haverá apenas uma fenomenologia da razão na qualidade de investigação crítica sobre a possibilidade de conhecimento" (MOURA, 2006, p. 15).

Na última fase da filosofia husserliana, embora já gestado em suas obras anteriores, aparece explicitado o conceito de "mundo da vida" (lebenswelt) no conjunto de ensaios $A$ crise das ciências europeias e a fenomenologia transcendental, de 1936. Husserl afirma que a oposição entre doxa e episteme herdada desde a antiguidade grega é a responsável pelo obscurecimento do "mundo da vida" devido à crescente valorização da razão no pensamento

\footnotetext{
"Uma das tarefas da dialética, como pensamento de situação, pensamento em contato com o ser, é sacudir as falsas evidências, denunciar as significações cortadas da experiência do ser, esvaziadas, e criticar-se a si mesma na medida em que se venha a tornar uma delas. Ora, esse o perigo que corre desde que se enuncia em teses, em significações unívocas, desde que se separe de seu contexto antepredicativo. É-lhe essencial ser autocrítica - e lhe é também essencial esquecê-lo desde que se torne aquilo que chamamos uma filosofia" (MERLEAU-PONTY, 1992, p. 93-94).

A relação entre o desenho e a criação do "lugar" para a arquitetura enfatiza a presença do arquiteto como criador, fundador de uma cultura, marca que impõe significações no mundo. "O que torna possível a experiência criadora á a existência de uma falta ou de uma lacuna a serem preenchidas, sentidas pelo sujeito como intenção de significar alguma coisa muito precisa e determinada, que faz do trabalho para realizar a intenção significativa o próprio caminho para preencher seu vazio e determinar sua indeterminação, levando à expressão o que ainda e nunca havia sido expresso" (CHAUI, p. 152-153).

Ver Los ojos de la piel: la arquitectura y los sentidos, de Juhani Pallasmaa; Cuestiones de percepción: Fenomenologia de la arquitectura, de Steven Holl; Atmosferas, de Peter Zumthor (que, embora não se dirija diretamente a Merleau-Ponty, a noção de "atmosferas" encontra-se com a obra Fenomenologia da percepção no sentido da relevância que o autor consagra aos conteúdos vividos e aponta para um corpo relacionado ao espaço e para a pujança do sensível).
} 
ocidental. A legitimação das validades pré-lógicas fundantes das verdades da ciência deslocam a ciência do seu lugar privilegiado instituinte de verdades absolutas para uma das práticas possíveis que se realizam no interior do "mundo da vida". Esse tema caracteriza o sentido da "experiência radical", todavia dissociado de uma redução última transcendental imposta por Husserl na interação da consciência com o mundo, como via de acesso à pureza de pensamento, ou seja, um "eu penso", um encontro efetivo com o "ego transcendental". Tal postura circunscreve a fenomenologia husserliana no âmbito das filosofias da consciência que será recusada por Merleau-Ponty.

O conceito "mundo da vida" husserliano, retomado por Merleau-Ponty, conta com o sujeito encarnado no mundo que antes de um "eu penso" revelará um "eu posso". Para o autor, as regiões mundanas não se reduzem a uma objetividade segunda, mas estão "longe de situar-se em uma instância 'transcendental' concebida por princípio extra mundana, em vez de ilharse em uma esfera de 'significações', doravante a filosofia será um discurso que fala 'do mundo, dos homens, e do espírito'” (MERLEAU-PONTY, 1985, p. 138). "Essas regiões mundanas [...] são consideradas domínios vividos por nós” (MOURA, 2006, p. 18). O sujeito a quem se refere Merleau-Ponty não será mais o sujeito epistemológico husserliano, mas um sujeito prático, encarnado no mundo. A transcendência coincidirá com a temporalidade e a "situação" do sujeito, pois "o mundo só é acessível àquele que está situado nele e esposa sua direção” (MERLEAU-PONTY, 1985, p. 492).

Diante desse cenário, evidencia-se a recusa de um observador absoluto, cosmotheoros (ser contemplativo) e percebe-se a valorização do sujeito participativo plenamente aderido à trama do mundo. Afrouxando-se os fios intencionais que ligam o sujeito ao mundo objetivo, a percepção revela-se pouco a pouco como realidade inacabada e transcorre sobre distintos pontos de vista. Tal situação aponta para a tese do perspectivismo, isto é, o encontro sujeito/objeto/mundo se realiza por meio de perfis e jamais encerra em si a ideia de um objeto "total" plenamente concluído. O caráter perspectivo aparece como propriedade essencial das coisas e faz que o percebido possua nele mesmo uma riqueza inesgotável, confere a possibilidade de um mundo mais rico.

Desenha-se, enfim, a trajetória do objeto indeterminado, primeiramente constituído numa consciência antitética rumo à constituição de sua unidade na consciência reflexiva. As críticas de Merleau-Ponty tanto ao intelectualismo como ao empirismo referem-se ao fato de que ambos passam em silêncio à constituição do objeto e acreditam possuir a clareza e a verdade do objeto para o qual a contingência nada acrescenta. Todavia, "nos dois casos, não nos instalamos na consciência em vias de apreender, isto é, não nos instalamos na percepção efetiva, pela simples razão de que nos dois casos, o objeto a quem se referem é o objeto completo e real" (MOUTINHO, 2006, p. 104). A filosofia merleau-pontiana instiga uma reflexão para o ensino de projeto no âmbito da arquitetura e urbanismo, revela-se fecunda, pois, o autor propõe uma maneira mais rica de abordar a ciência e evidencia na arte a gênese de um saber fundamental à própria filosofia.

Como a ação de projetar situa-se na fronteira entre arte e ciência, faz-se necessário a construção de um solo rico tanto para a absorção do conhecimento pelos alunos quanto para a criação de um projeto arquitetônico que leve em consideração o mundo vivido, o cotidiano dos alunos, a percepção, a reabilitação do sensível, recuo constituinte da gênese do mundo objetivo. Merleau-Ponty (1995) recusa o "movimento natural do conhecimento que atravessa cegamente as operações perceptivas para ir diretamente ao seu resultado teleológico" (p. 71, 91).

Os alunos dos primeiros semestres do curso de Arquitetura e Urbanismo, por possuírem uma abertura intencional e flexível para o conhecimento em relação aos conteúdos específicos das disciplinas de projeto, constituem-se num ótimo exemplo da possibilidade de encontro fortuito com o mundo, pois, 
O saber pós-moderno não é somente instrumento de poderes. Ele aguça nossa sensibilidade para as diferenças e reforça nossa capacidade de suportar o incomensurável. Ele mesmo não encontra sua razão de ser na homologia dos experts, mas na paralogia dos inventores (LYOTARD, 1986, p. xvii).

\section{A METODOLOGIA DE ENSINO E A FENOMENOLOGIA DE MERLEAU-PONTY}

\section{1"a etapa da transmissão de conhecimento: a valorização da experiência - percepção - o encontro primordial do sujeito com o mundo}

No prefácio da Fenomenologia da percepção, Merleau-Ponty pergunta: 0 que é fenomenologia? A primeira ordem dada por Husserl à fenomenologia de retornar "as coisas mesmas" constitui-se como crítica à ciência que no final do século XIX desenvolvia-se segundo o critério objetivista baseado nas ciências da natureza, ou seja, excluía de sua análise a interferência de aspectos subjetivos considerados não científicos. Para Merleau-Ponty, no materialismo filosófico os fenômenos humanos equiparados a objetos físicos excluem a intencionalidade humana criadora desses mesmos objetos. Os seres humanos estabelecem entre si relações puramente objetivas, reificadas. Numa outra polaridade, a concepção cartesiana sobre a existência essencialmente mental, acessível a uma única individualidade, consequentemente estabelece a cisão entre mente e corpo, sujeito e objeto cuja evidência possível das ideias encontra-se na mente humana.

Segundo Merleau-Ponty, a fenomenologia desenvolveu-se a partir de uma crise da cultura que erradicava seus próprios fundamentos relacionando-se com seus objetos de forma causal, vistos em sua exterioridade confundidos com sua própria natureza. A verdadeira filosofia constitui-se em reaprender a ver o mundo, significa o fim da cisão sujeito/objeto, alma/corpo, fato/ideia, inteligível/ sensível. Antes do saber intelectual a percepção estabelece-se como via de acesso à verdade e destitui a consciência reflexiva de seu "projeto de posse intelectual do mundo". O mundo vivido, pré-objetivo, autóctone, não mais constituído por nenhuma instância acima dele, não pode mais ser reduzido. O sujeito merleau-pontiano é prático, encarnado num corpo que se encontra numa determinada "situação" no mundo, pois a "consciência é o ser para a coisa por intermédio do corpo" (MERLEAU-PONTY, 1999, p.193). Esse novo locus do sujeito converte-se na ideia da "carnalidade" que surge no cenário filosófico desde suas primeiras reflexões. Trata-se de transcender a ideia do quale puro e legitimar uma nova experiência, a da consanguinidade carnal entre o corpo e o mundo, reversibilidade entre interior e exterior, não mais pensamento de sobrevoo, mas descida a terra, abertura para uma reflexão radical. A priori o que se busca "não é encadear conceitos, mas descrever a mistura da consciência com o mundo, seu engajamento num corpo, sua coexistência com os outros” (Idem, 1996, p.75).

De acordo com o professor dr. Sílvio Soares Macedo ${ }^{6}$, os alunos do curso de Arquitetura e Urbanismo (que têm entre 18 e 19 anos) ingressam na universidade sem qualquer conhecimento sobre o conceito de espacialidade e questões como escala, tipologias, gabaritos. Ainda não existem incorporados nos estudantes os fundamentos necessários para o ato de projetar. Isso representa que há conhecimentos novos a serem conquistados.

Nesta primeira etapa da construção do conhecimento, nota-se uma abertura por parte do professor Sílvio ao propor exercícios para os alunos utilizando-se de jogos teatrais, expressão corporal e estimulação sensorial

Palestra ministrada pelo professor dr. Sílvio Soares Macedo na disciplina de Pedagogia para a Arquitetura no segundo semestre de 2012 . 
que apontam para a formação de um sistema de equivalências entre o corpo, natureza e espaço construído. Essas experiências conferem aos estudantes a compreensão do conceito de "espaço", a possibilidade de sua abstração e sua aplicação direta no ato de projetar. Estabelece-se, dessa forma, uma experiência espacial a partir do Ser que "não é mais esse meio das coisas simultâneas que poderia ser dominado por um observador absoluto, igualmente próximo de todas elas, sem ponto de vista, sem corpo, sem situação espacial, pura inteligência” (MERLEAU-PONTY, 2004, p. 15), mas legitimam-se "as relações orgânicas entre sujeito e o espaço a esse poder do sujeito sobre seu mundo que é a origem do espaço" (MERLEAU-PONTY, 1999, p. 338).

A apreensão das regras e normas inerentes da geometria para a construção do conceito de espaço, representada pelos desenhos operacionais para o canteiro situa-se numa esfera abstrata própria das ciências. Para o professor Sílvio, o conceito abstrato do espaço origina-se no seio da experiência efetiva dos alunos e não exclui a possibilidade de seu sentido ser contingente, ou seja, que ele possa se formar no curso dos acontecimentos, das atividades propostas para a disciplina como desafios que excluem uma relação prévia de causa e efeito. De acordo com o estudante Gabriel Vilela que frequentou a disciplina AUP 652:

A dificuldade da interface entre o desenho e o espaço é um desafio muito complexo que só é vencido pelos estudantes com muito esforço, esse é um grande desafio encontrado em todo o campo da arquitetura. O professor Silvio tenta trazer isso através da vivência, fazendo que cada desenho passe a significar para o aluno alguma dimensão sensível. Me lembro bem de que em um momento em que meu grupo teve um problema de escala o Silvio nos levou até o jardim e começou a discutir as dimensões com o que estava a nossa volta (informação verbal) ${ }^{7}$.

A "experiência” adquire assim estatuto de cidadania e não pode se definir mais como passividade, resposta aos estímulos sensoriais externos como era para o empirismo nem exploração intelectual do mundo como era para o intelectualismo, mas, entra em cena como transmissora de um saber que encontra relações e equivalências com o corpo e com a natureza e o espaço construído.

Para Merleau-Ponty a ciência atravessa cegamente as operações perceptivas e separa rigidamente as categorias da sensibilidade e do entendimento. Será necessário redefinir essas categorias, diluir a fronteira clássica, entrelaçar os conteúdos da experiência apresentados na esfera do sensível e o engendramento de relações de diversas ordens encontrado na esfera do entendimento. As relações lógicas excluem a contingência dos acontecimentos. Da experiência nasce o sentido que se encontra intimamente ligado à existência. O sensível encontra-se diante do Ser e não no plano da consciência, situa-se "entre" o domínio do sujeito e objeto, "entre" as oposições clássicas objetivo/subjetivo, exterior/interior. É importante destacar que a sensação para o autor constitui-se como intencional "porque encontro no sensível a proposição de um certo ritmo de existência", uma forma de existência que é sugerida para o sujeito que se reporta a um ser exterior seja para abrir-se ou fechar-se a ele (MERLEAUPONTY, 1999, p. 288).

A camada da percepção para os alunos da disciplina AUP 652 apresenta uma abertura inicial ao mundo que ao final da disciplina revelará seu trajeto teleológico em direção ao ser determinado, ou seja, aos objetivos finais da disciplina clarificados e assimilados pelos alunos por meio da reflexão.

De acordo com Merleau-Ponty, o corpo projeta significações no mundo exterior e é sujeito de percepção. Tese que afasta a compreensão cartesiana 
do corpo como objeto entre outros objetos, partes extra partes que somente admite relações mecânicas. Apresentado pelo autor como "veículo de ser no mundo" exibe uma situação no mundo em face de suas tarefas que remete para um conceito de intencionalidade, pois

É meu olhar que subtende a cor, é o movimento de minha mão que subtende a forma do objeto, ou antes, meu olhar acopla-se à cor, minha mão acopla-se ao duro e ao mole, e nessa troca entre o sujeito da sensação e o sensível não se pode dizer que um haja e o outro padeça, que um dê sentido ao outro. Sem a exploração do meu olhar ou de minha mão, e antes que meu corpo se sincronize a ele, o sensível é apenas uma solicitação vaga (Ibidem, p. 288).

Questões como o reconhecimento da espacialidade e do uso das escalas para a finalidade do projeto no âmbito da arquitetura e urbanismo verificam-se nas atividades propostas pelo professor Sílvio aos estudantes favoráveis à descoberta do caráter heterogêneo do espaço, investigação de uma experiência espacial originária aquém da distinção clássica entre forma e conteúdo.

De acordo com Merleau-Ponty (2004), a ciência clássica distingue claramente o espaço e o mundo físico, ou seja, separa a noção de forma e conteúdo. À luz dessa perspectiva "o espaço é o meio homogêneo onde as coisas estão distribuídas segundo três dimensões e onde elas conservam sua identidade a despeito de todas as mudanças de lugar" (p. 10). Nota-se uma inflexão do autor quando

Com as geometrias ditas não euclidianas, chega-se a conceber como que uma curvatura própria do espaço, uma alteração das coisas devido apenas ao seu deslocamento, uma heterogeneidade das partes do espaço e de suas dimensões que não são intercambiáveis e afetam os corpos que nele se deslocam com algumas transformações (MERLEAU-PONTY, 2006, p. 11).

Abre-se então um mundo onde os objetos prescindem de uma identidade absoluta e as noções de forma e conteúdo encontram-se mescladas, e que "não oferece mais essa estrutura rígida que lhe era fornecida pelo espaço homogêneo de Euclides” (Ibidem, p. 11). Segundo o autor, as coisas e o espaço se embaralham e não se faz a distinção entre "o espaço das coisas no espaço" (Ibidem, p. 11). O espaço heterogêneo representa os conteúdos vividos, um meio de coexistência das coisas, horizonte da articulação dos sentidos e acessível por meio do corpo.

Segundo Marina Caraffa, estagiária do programa do PAE,

A experimentação física, adotada como estratégia metodológica, é indutora da percepção dos alunos. A relação do corpo com o espaço é explorada com exercícios simples, como verificar a dimensão entre os pilares da FAU a partir de medidas tiradas a partir das passadas, ou verificar a densidade de ocupação do espaço através de experiências com os próprios alunos em pé nas cadeiras da sala. Além disso, os exercícios de observação exteriores, como andar pelo campus observando a organização do espaço a partir da composição da vegetação, permitem aproximação das relações de escalas que podem ser percebidas a partir da interação do corpo com o espaço. Dessa maneira, os exercícios permitem não só a apreensão do conhecimento proposto como gera uma aproximação entre aluno e professor (informação verbal) ${ }^{8}$. 
Nesse momento, o espaço do geômetra deve ser posto entre parêntesis, pois o espaço e os objetos não se constituem apenas como objetos de pensamento, mas evocam uma conduta por parte dos alunos, uma abertura inicial e uma forma de conhecimento que irá legitimar a camada da percepção como solo originário da criação do projeto.

A aproximação entre os alunos e o professor, como destaca a estagiária Marina Caraffa, ocorre por meio da constatação de um mundo único, um mundo público que ultrapassa os sujeitos envolvidos nas suas ações, um mundo mais velho que a consciência.

\section{2ำ etapa da transmissão do conhecimento: criação - expressão - linguagem}

$\mathrm{Na}$ segunda etapa de trabalho os estudantes organizados em equipes encaminham-se para o estúdio onde desenvolvem efetivamente o exercício do desenho, ancorados em questões vivenciadas na primeira parte da aula. Para a ação projetual composta de partes que irão inteirar-se num todo complexo, exigem-se diálogos pedagógicos, ou seja, a condução dos desenhos de forma orientada.

Segundo professor dr. Sílvio ${ }^{9}$ Soares Macedo, o potencial criativo ${ }^{10}$ dos alunos do curso de Arquitetura e Urbanismo deve ser estimulado, pois comporta sua maior riqueza, uma mescla de aspectos subjetivos e objetivos que serão organizados na forma de projeto.

O contato com o mundo e a percepção transfigurados em ideias no suporte papel constitui o primeiro gesto fenomenológico do arquiteto. A experiência do desenho na forma de croquis é considerada um âmbito expressivo, relaciona-se diretamente ao criar e exige um sujeito motivado e "em situação". Ao legitimar um "sentido inédito", Merleau-Ponty (1999) oporá a "linguagem autêntica” (responsável pela criação) a uma linguagem "segunda" (adequação a um signo pré-estabelecido), todavia, a linguagem primeira aparecerá "quando, em vez de copiar um pensamento, deixa-se por ele desfazer e refazer” (1999, p. 93). A linguagem para o filósofo não se realiza diretamente como notação do real, mas obliquamente, isto é, torna presente o ausente. A sua significação direta revela sua capacidade secundária. O escritor e o arquiteto alojam-se entre signos constituídos na sociedade e na cultura, porém a linguagem autêntica presume uma capacidade de ordenação nova desses signos, uma criação "instituinte" e caracteriza-se essencialmente

em nossa capacidade de abandono das garantias, em nossa capacidade de autenticidade, de contínua educação em tal autenticidade, de contínuo confronto entre esta e nossas escolhas no mundo, fora dos refúgios moralísticos, ideológicos, religiosos que o nosso medo e a nossa preguiça constroem continuamente para nós (GREGOTTI, 2010, p. 28).

\section{No interior da realidade instituída}

Há o momento instituinte no qual o Ser vem a ser: para que o ser do visível venha à visibilidade solicita o trabalho do pintor, para que o Ser da linguagem venha à expressão pede o trabalho do escritor;

Palestra realizada na disciplina de Pedagogia aplicada para a arquitetura, novembro 2012

10 Para o arquiteto Vittório Gregotti, o exercício da criação apresentado diverso do raciocínio científico e do discurso lógico insere-se num conceito de razão alargada, apontando uma necessidade de fundação de uma "pedagogia da invenção". "O exercício da invenção é central porque parte da percepção e da memória em direção ao que ainda não é, mas este exercício não é casual ou gratuita violação do já constituído, mas sim busca contínua de uma ordem nova e diversa, instituição de uma nova possibilidade, de uma nova experiência do mundo acionada materialmente. Não há nenhuma razão em julgar que a invenção, enquanto bem social inexaurível, não possa ser cultivada ou ensinada e sobretudo convertida em disciplina, quer dizer, traduzida na única forma de encontro possível com o problema arquitetônico" (GREGOTTI, 2010, p. 29). 
para que o Ser do pensamento venha à inteligibilidade, exige o trabalho do filósofo" (CHAUÍ, 2002, p. 152).

Assim, para que o Ser do espaço torne-se habitável, exige-se o trabalho do arquiteto. Segundo Gregotti, o resultado para os arquitetos de um contato com o mundo franco e autêntico é estabelecido "pelas novas possibilidades de relação que lograram instituir, na capacidade de tornar acessível a muitos o espetáculo de que participam sem vê-lo e sobretudo sem dele usufruir" (GREGOTTI, 2010, p. 28-29). Enfim, a criação "fazendo vir ao Ser aquilo que sem ela nos privaria de experimentá-lo" (CHAUÍ, 2002, p. 153).

Além da invenção como proposta pedagógica para o ensino do projeto, à medida que o processo projetual avança, o desenho estabelece-se de forma orientada com critérios conceituais e gráficos consistentes direcionados aos objetivos a serem alcançados pelos alunos. Nesse nível as representações gráficas exigem um grau de subjetivação e abstração elevado, o que é favorecido pelos fundamentos absorvidos pelos estudantes na primeira etapa do trabalho. Relações complexas estabelecem-se na transcrição para o papel de conceitos como: escala, dimensões, proporções, aspectos pertencentes ao sítio, cortes topográficos, incidências solares, tipologias, paisagem, espaço público e privado, circulação, forma, natureza, cidade, perfil do futuro usuário etc. Longe agora de uma consciência privada, essas relações apontam para o caráter comunicativo do projeto de arquitetura e urbanismo.

As equipes mantêm-se o tempo todo ocupadas com exercícios na forma de desafios sugeridos pelos professores na primeira etapa do trabalho. $\mathrm{O}$ atendimento não ocorre de forma linear, mas assimétrica. Os professores e estagiários circulam pelas equipes e agregam aos projetos diferentes pontos de vista. Desse modo, verifica-se uma ação transformadora da linguagem, que se estabelece na consciência de um mundo compartilhado. No contato com os objetos culturais, o ser humano abdica de seu mundo privado e reconhece outros seres estabelecendo relações, significados em que a linguagem desempenha papel central. Um autêntico diálogo "me conduz a pensamentos que eu não me acreditava, de que eu não era capaz, e às vezes sinto-me seguido num caminho que eu próprio desenhava e que meu discurso, relançado por outrem está abrindo para mim" (MERLEAU-PONTY, 1992, p. 24).

$\mathrm{Na}$ fenomenologia da linguagem desenvolvida por Merleau-Ponty, o mundo compartilhado estabelece-se na comunicação de uma fala que impõe um descentramento do sujeito, não mais dado a si mesmo, mas, engajado no mundo. Essa fala rompe o silêncio tornando-se portadora de sentidos outrora não sabidos, revelados numa ação coletiva, na coexistência entre sujeitos, experiência genuinamente intersubjetiva ${ }^{11}$. Na passagem da percepção para a linguagem estabelece-se a comunicação e um poder da fala de dizer mais do que diz termo por termo, um poder de "se superar ela própria quer se trate de lançar o outro em direção ao que sei e que ele ainda não compreendeu ou de orientar-me eu mesmo em direção ao que vou compreender" (MERLEAU-PONTY, 1995, p. 216). Esse potencial da comunicação evidencia o comprometimento dos professores em relação aos alunos e fortalece os laços que unem o conhecimento aos conteúdos específicos do projeto.

\section{$3^{\circ}$ etapa da transmissão do conhecimento: reflexão}

\footnotetext{
Segundo Moutinho, “a partir de 1950, Merleau-Ponty interditará o salto (dado pela fenomenologia...) da coexistência entre sujeitos para o interior da consciência, para si aquém da situação comum. A universalidade pode então adquirir um sentido novo - ela atravessa toda minha experiência - e não foi por outra razão, como vimos que Merleau-Ponty pode falar em "intercorporeidade” e a subjetividade transcendental - segundo a solução merleau-pontiana do enigma de Husserl, tornou-se efetivamente intersubjetividade. Daí a solução nova para o acordo entre finitude e universalidade: não mais uma mistura, mas um acordo efetivo, na justa medida em que o sujeito foi descentrado, em que apareceu uma espontaneidade que o conduz, espontaneidade que pode reunir, enfim toda a pluralidade das mônadas” (MOUTINHO, 2006, p. 402-403, grifo do autor).
} 
Na terceira fase das atividades da disciplina AUP 652, as equipes dos alunos retornam para a sala de aula para exporem e refletirem sobre 0 trabalho realizado no período da aula. Experiência que se revela ao fazer-se aberta e democrática, sempre retomada e questionada, inacabada, que "dá o que pensar".

No ensaio As ciências do homem e a fenomenologia, Merleau-Ponty (1973) aponta para uma crise da razão ${ }^{12}$ ocasionada pela ruptura entre ciência e filosofia, pois o "ser" objetivo da ciência toma o lugar do Ser, desse modo, instaura-se o primado da "pura exterioridade", que, por conseguinte, aniquila o "primado da interioridade" pautado pela filosofia. A proposição dessa "crise" de Merleau-Ponty conduz a um conceito de "razão alargada”, pois será o desenvolvimento das ciências que escapará da pura exterioridade assim como a filosofia não poderá manter-se na interioridade de um sujeito transcendental. Para o filósofo, ciência e filosofia envolvemse. $\mathrm{O}$ autor cita o exemplo do sociólogo que elabora filosofia à medida "que ele é encarregado não apenas de notar os fatos, mas, de compreendê-los. No momento da interpretação, ele próprio já é filósofo" (MERLEAU-PONTY, 1985, p. 127). Essa nova relação entre ciência e filosofia estabelecerá o fim da crise da razão.

Os projetos das equipes de trabalho como forma aberta revelam uma organização formal ambígua, pois "a forma arquitetônica de um fenômeno é, por um lado, o modo como as partes e os estratos estão dispostos, mas também o poder de comunicação daquela disposição" (GREGOTTI, 2010, p. 27-28). O sentido da experiência do projeto, de acordo com o arquiteto Vittório Gregotti (2010), exige um contínuo esforço do arquiteto, pois “o grau de significatividade desta ordenação revela-se na forma, em sua capacidade de distanciar-se e negar aquilo que é instituído segundo uma medida crítica que conserve sua própria capacidade de relacionamento de atração frente ao existente que contesta” (GREGOTTI, 2010, p. 27).

Nessa última etapa da transmissão do conhecimento na disciplina AUP 652 nota-se o desenvolvimento da reflexão crítica por parte dos alunos, a construção de um pensamento que conta com a experiência efetiva dos alunos no encontro com o espaço dos conteúdos vividos, habitado por um corpo e aquele da geometria, dos códigos específicos de representação para a arquitetura, o espaço abstrato da ciência. A cada aula o movimento da percepção, da expressão e da reflexão faz-se presente, as operações presentes no ato de projetar tornam-se significativas e no final do semestre estabelecem relações entre si.

A ideia de uma "razão alargada" proposta por Merleau-Ponty aponta para uma nova redefinição da ciência da filosofia e da arte, cuja principal característica não é "encadear conceitos, mas descrever a mistura da consciência com o mundo, seu engajamento num corpo, sua coexistência com os outros" (1996, p. 75). Sempre inquieta, inquisitiva, brota das próprias coisas e não pode ser indiferente ao mundo ${ }^{13}$. Essa razão está fora de qualquer relação causal, estabelecida de forma linear, mas avança obliquamente, quer dizer, as questões nunca se constituem frontalmente para o sujeito, o que seria uma "posse intelectual" do mundo, mas, incluem o estrato pré-reflexivo, pré-objetivo da experiência do sujeito. O mundo, assim, se configura como unidade autóctone ${ }^{14}$, isto é, não deve ser

\footnotetext{
Para Moura (2006), Husserl antes de 1936 designa a crise dos fundamentos da ciência a partir do momento que a ciência começa a operar com signos exteriores "que mantêm uma relação puramente arbitrária com o seu designado, que não têm nada a ver com o conteúdo nem com as propriedades do objeto, e que para tanto apenas o designam, sem o caracterizarem” (p. 55).

13 Edgar Morin (2011), na esteira de Merleau-Ponty, afirma que a verdadeira racionalidade possui limites e que o espírito humano não pode ser onisciente, pois, a realidade implica mistério. Segundo o autor, "a verdadeira racionalidade é aberta e dialoga com um real que resiste a ela. Opera um vaivém incessante entre a lógica e o empírico; ela é fruto de um debate argumentativo de ideias e não propriedade de um sistema de ideias. A razão que ignora os seres, a subjetividade, a afetividade, a vida, é irracional” (pp. $55,56)$

14 "No interior da filosofia husserliana o Mundo vivido representa um espaço original, mas não delimita, contudo, uma região autônoma, uma região que traga em si mesma a chave de seu sentido. Após delinear o universo do mundo da vida, Husserl o caracteriza como etapa a ser igualmente 'reduzida' e a partir da qual chegaremos à subjetividade transcendental” (MOURA, p. 131).
} 
regulado ou organizado por qualquer instância superior a ele (princípios de associações ou um Ego transcendental, dotado de sentido imanente), ou seja, não pode ser reduzido.

Com o estudo de caso da disciplina AUP 652 colocam-se as questões: como enriquecer o solo para a ação projetual dos futuros arquitetos? Ampliar a percepção, estabelecer um acordo entre sensível e inteligível, incentivar a expressão, a criação, a visão crítica dos estudantes? Enfim, fomentar uma "educação para a autenticidade" a que se refere o arquiteto Vittório Gregotti, quando muitas universidades na atualidade transformam-se em verdadeiras empresas e possuem o único foco de "formar arquitetos para o mercado" pode-se facilmente indagar se formam arquitetos ou projetistas?

\section{REFERÊNCIAS}

CHAUÍ, M. Experiência do Pensamento: ensaios sobre a obra de Merleau-Ponty. São Paulo: Martins Fontes, 2002

GREGOTTI, V. Território da arquitetura. São Paulo: Perspectiva, 2010.

LYODARD, J.-F. O pós-moderno. Rio de Janeiro: José Olympio, 1986

MERLEAU-PONTY, M. As ciências do homem e fenomenología. São Paulo: Saraiva, 1973

MERLEAU-PONTY, M., Signes: Paris: NRF Gallimard,1985.

MERLEAU-PONTY, M. O primado da percepção e suas consequências filosóficas. Campinas: Papirus, 1990.

MERLEAU-PONTY, M. Signos. São Paulo: Martins Fontes, 1991.

MERLEAU-PONTY, M. O visível e o invisível. São Paulo: Perspectiva, 1992.

MERLEAU-PONTY, M. Sens et non sens. Paris: Gallimard, 1996.

MERLEAU-PONTY, M. Fenomenologia da percepção. São Paulo: Martins Fontes, 1999.

MERLEAU-PONTY, M. A prosa do mundo. São Paulo: Cosac Naify, 2002.

MERLEAU-PONTY, M. O olho e o espírito. São Paulo: Cosac Naify, 2004.
MERLEAU-PONTY, M. A estrutura do comportamento. São Paulo: Martins Fontes, 2006.

MONTANER, Josef Maria e MUXÍ, Zaida. Arquitectura y política ensayos para mundos alternativos. Barcelona: Editorial Gustavo Gili, 2012.

MORIN, E. Rumo ao abismo? Ensaio sobre o destino da humanidade. Rio de Janeiro: Bertrand Brasil, 2011.

MOURA, C. A. R. Husserl: significação e fenômeno. Curitiba, Dois Pontos, v. 3, n. 1, p. 37-61, abr. 2006. Disponível em: <http:// ojs.c3sl.ufpr.br/ojs/index.php/doispontos/ article/download/5172/3889>. Acesso em: 2 fev. 2016

MOURA, C. A. R. Apresentação. In: MOUTINHO, L.D.S. Razão e experiência: ensaio sobre Merleau-Ponty. Rio de Janeiro: Unesp, 2006

MOURA, C. A. R. Intencionalidade e existência: Husserl e Merleau-Ponty. In: VALVERDE, M. (Org). Merleau-Ponty em Salvador. Salvador: Arcádia, 2008. MOUTINHO, L. D. S. Razão e experiência: ensaio sobre Merleau-Ponty. Rio de Janeiro: Unesp, 2006.

SILVA, C. A. de F. A Carnalidade da reflexão: ipseidade e alteridade em Merleau-Ponty. São Leopoldo: Nova Harmonia, 2009. 